\title{
1. Introduction: the interaction between welfare deservingness and welfare policy
}

\section{Tijs Laenen}

Society lays a modest table at which all can sup and a high table at which the deserving can feast. (Kenneth E. Boulding, 1962: 83)

More than half a century after it was first written, Boulding's (1962) argument outlined in the above epigraph serves as an excellent onesentence summary of the present book. As should become clear in the course of the introduction, Boulding's statement is reflected in both public opinion and public policy on social welfare. ${ }^{1}$ Opinion-wise, past attitudinal research has consistently shown that even though people generally consider most of their fellow citizens to be deserving of social welfare, some particular groups - notably the old, the sick and the disabled - have always been considered more deserving of it compared with the able-bodied unemployed of working age. Policy-wise, it is argued that welfare states have, throughout history, tended to offer somewhat more generous and less conditional social protection to those groups that are deemed most deserving by the general public. The core proposition of this book is that the remarkable congruence between public opinion and public policy in the social welfare domain is no coincidence, but can instead be read as the product of a reciprocal relationship between popular deservingness opinions, on the one hand, and social welfare policies, on the other. After clarifying how Boulding's quote manifests itself in public opinion as well as in public policy, the introduction concludes with the presentation of a heuristic model and an outline of the remainder of the book. 


\subsection{BOULDING IN PUBLIC OPINION: ALL ARE DESERVING OF SOCIAL WELFARE, BUT SOME MORE THAN OTHERS}

For several decades now, the welfare attitudes of ordinary citizens, and their causes and consequences, have been a topical object of academic study. In spite of its long-standing tradition, the world of welfare attitudes remains rife with ongoing debates about - to mention just a few issues - the causal relationship between welfare opinions and political predispositions (Jaeger, 2008), the institutional embeddedness of such popular preferences in welfare regimes (Larsen, 2006), the effect of the state of the economy on people's welfare generosity (Blekesaune, 2007), the interrelations between the different dimensions of welfare state legitimacy (Roosma, 2016) and the role played by self-interest in welfare opinion formation (Sears and Funk, 1991). Amidst all this controversy, one of the most consistent and well-documented findings is that some social welfare policies are more popular than others: in particular, those targeted at the old, the sick and the disabled vis-à-vis those geared towards able-bodied people of working age. One of the first to expose this strikingly stable pattern in public support was Coughlin (1980), who found that in the six industrialized nations included in his pioneering review of public opinion polls, old-age pensions and healthcare were far more popular than unemployment benefits and social assistance. To emphasize that this rank order cuts across national borders, time periods, ideological divides and class cleavages, Coughlin (1980: 117) called it a 'universal dimension of support'. In the years to follow, the same empirical pattern was observed time and time again in a multitude of public opinion studies, conducted in different countries and different years, and using a broad variety of data and measurements (Bean and Papadakis, 1998; Blekesaune and Quadagno, 2003; Blomberg and Kroll, 1999; Cook, 1979; Ebbinghaus and Naumann, 2018; Gilens, 1999; Golding and Middleton, 1982; Goldschmidt, 2015; Hills, 2002; Jaeger, 2007; Jeene and van Oorschot, 2013; Jordan, 2013; Mau, 2003; Pettersen, 2001; Rothstein, 1998; Svallfors, 1991, 2004; Taylor-Gooby, 1985, 2001, 2011a; van Oorschot, 2006a; van Oorschot and Meuleman, 2012a; Wendt et al., 2011). ${ }^{2}$

Why, however, are welfare policies targeted at the old, sick and disabled more popular than those aimed at the able-bodied unemployed? Contrary to the consensus that exists around the empirical pattern, the issue of how to explain that pattern has sparked much more scholarly debate. According to Cook and Barrett (1992), there are at least four major explanations as to why some social welfare programmes are supported more than others. The first explanation is rooted in the oft-cited idea that citizens support those 
welfare programmes that they are most likely to benefit from. Because nearly everyone is destined to grow old and runs the risk of becoming ill or disabled, self-interest logic dictates that welfare schemes such as old-age pensions and healthcare receive tremendous public support (Jaeger, 2007; Jensen and Petersen, 2017; Wendt et al., 2011). Becoming unemployed or living in poverty, by contrast, tend not to be seen as social contingencies to which all are equally susceptible, but are known to disproportionately affect the lower socioeconomic strata (Jensen and Petersen, 2017; Korpi and Palme, 2003). As a result, the upper and middle classes are not as likely to consider unemployment and social assistance schemes as good value for their (tax) money, and accordingly, express lower support for them. The second explanation starts off from the antipode of self-interest in welfare attitudes literature: ideology. The core argument is that social welfare programmes for the working-age, able-bodied unemployed go against the conservative-ideological doctrine that all those who are capable of working should do so in order to be self-sufficient and not dependent on state welfare (Gilens, 1999; Mead, 1986; Murray, 1984). Programmes for the old, sick and disabled, by contrast, offer benefits to those who are either permanently or temporarily - incapable of work, and thus garner support across ideological divides (Jensen and Petersen, 2017; Wendt et al., 2011). Previous research has indeed shown that while almost all - from egalitarians to anti-egalitarians, from collectivists to individualists and from liberals to conservatives - agree that governments are responsible for providing old-age pensions and healthcare, there is much more ideological opposition to unemployment benefits and social assistance (Blekesaune and Quadagno, 2003; Cook and Barrett, 1992). The third explanation emphasizes popular performance evaluations and assumes that citizens support those welfare programmes that they believe function well in terms of effectiveness, cost efficiency, administrative complexity, procedural fairness and so on (Rothstein, 1998). Prior studies suggest that unemployment and social assistance benefits are judged to perform worse than pension, healthcare and disability schemes, especially with regard to perceived fraud and abuse, presumably because they are typically more selective in design and/or are targeted at groups that the public see as less trustworthy (Cook and Barrett, 1992; Roosma et al., 2014b).

The trustworthiness argument already touches on the fourth and final explanation, which is at the core of this book and holds that welfare programmes for the old, the sick and the disabled are more popular than those for the able-bodied unemployed, because the former are deemed to be more deserving of social welfare by the general public (Larsen, 2006; van Oorschot, 2000, 2006a). More specifically, the old, sick and disabled are evaluated much more favourably on five crucial deservingness dimensions 
underlying citizens' welfare preferences: Control, Attitude, Reciprocity, Identity and Need; also known as the 'CARIN criteria' (van Oorschot et al., 2017). A brief comparison between the elderly and the unemployed should, for now, suffice to illustrate the deservingness logic. First, it is obvious that the two groups hold disparate positions on the continuum of personal control: while old age is a biologically determined life event, joblessness is a condition that stems from someone's (lack of a) position in the labour market, and can thus be attributed to structural (e.g., economic downturns) and/or individual (e.g., laziness) causes (Jensen and Petersen, 2017). Second, the stereotypical public image of the grateful, docile pensioner stands in stark contrast to the mental picture of the more deviant, out-of-work youngster (the attitude criterion) (Jeene and van Oorschot, 2015; Larsen, 2008b). Third, a common assumption is that the elderly have contributed more to society than the unemployed during their active labour and parenting careers (the reciprocity criterion) (van Oorschot, 2000, 2006a). Fourth, people generally find it easier to identify with the elderly than with the unemployed, simply because nearly everyone has some kind of personal contact with the former and most of us will grow old ourselves (the identity criterion). Last, the elderly are often perceived to have special age-related health needs in addition to their financial needs, and are therefore evaluated more positively on the need criterion (van Oorschot, 2000, 2006a). Even though this book focuses on the deservingness explanation, it does not disregard the other explanatory frameworks, as they are clearly not 'mutually exclusive' and 'each makes its own unique contribution to our understanding of support for social welfare' (Cook and Barrett, 1992: 56). Because the explanatory power of a theoretical framework is only assessed to the fullest when it is compared with that of alternative frameworks, throughout this book the deservingness explanation of public support for social welfare is juxtaposed with the competing, or put differently, the complementary explanations of self-interest, ideology and performance evaluations.

It is crucial to note, however, that even though the able-bodied unemployed are seen as relatively less deserving, they are generally not judged to be undeserving in an absolute sense, ${ }^{3}$ and the social welfare programmes targeted at them may be relatively less popular, but they are not unpopular (Appelbaum, 2001; Mau, 2003; Wendt et al., 2011). ${ }^{4}$ Prior studies consistently demonstrate that most citizens do feel some sympathy and concern for the fate of the able-bodied of working age, and demand that governments provide them with welfare benefits and services. Just a few examples should serve to illustrate this pivotal point. In the American context, Cook and Barrett (1992) unearthed a clear bifurcation between, on the one hand, a number of extremely well-liked social welfare programmes for the old, sick and disabled (i.e., Medicare, Medicaid, Supplementary 
Security Income and Social Security) and, on the other hand, some comparatively less popular programmes for the able-bodied unemployed (i.e., Unemployment Insurance, Aid to Families with Dependent Children (AFDC) and Food Stamps). However, there is strong, underlying support for all social welfare programmes, including those for the working-age, able-bodied. ${ }^{5}$ Most Americans were in favour of either increasing or maintaining Unemployment Insurance ( 87 per cent), AFDC ( 84.5 per cent) and Food Stamps (75.6 per cent), and, perhaps even more remarkably, about one in three otherwise notoriously tax-averse Americans reported a willingness to pay higher taxes in order to avoid cuts in AFDC. A second example takes us from the United States to post-communist Europe, where, as shown by Lipsmeyer (2003), unemployment policies received markedly less public support than healthcare and old-age pensions across different countries, age cohorts and income levels. Nevertheless, in most of the post-communist societies investigated, vast majorities also considered it to be governments' responsibility to provide a decent standard of living for the unemployed, and relatively large proportions felt that spending on unemployment benefits ought to be increased. Likewise, Blekesaune and Quadagno (2003: 423, emphases added) concluded that 'the general picture among the industrialized nations studied is one of overwhelming support for welfare state policies for the sick and old, and generally positive attitudes towards welfare policies for the unemployed' (see also Fraile and Ferrer, 2005). A third and final example focuses on the Netherlands, where Roosma and Jeene (2017) observed that the disabled are not only granted more social rights than unemployed people and social assistance recipients, but are also shown considerably more leniency when it comes to the workrelated obligations they are required to fulfil. Even so, about 60 per cent of the Dutch public felt it was society's duty to endow the unemployed and those on social assistance with financial aid, despite being reminded of welfare retrenchment and the scarcity of resources. What these examples suggest is that, to paraphrase Boulding (1962: 83), the general public seems to want society to set a modest table for all, including the able-bodied unemployed, but a high table for the deserving old, sick and disabled.

\subsection{BOULDING IN PUBLIC POLICY: ALL RECEIVE SOCIAL WELFARE, BUT SOME MORE GENEROUSLY AND LESS CONDITIONALLY THAN OTHERS}

Setting a modest table at which all can sup and a high table at which the deserving can feast ${ }^{6}$ seems also to have been standard policy practice 
throughout the history of the welfare state. From the early poor laws to contemporary and well-developed welfare states, the same groups that are considered highly deserving in the public's view (i.e., the old, the sick and the disabled) have very frequently been offered more generous and less conditional social welfare compared with those deemed less deserving (i.e., the able-bodied unemployed) (Cook, 1979; Gans, 1995; George, 1996; Jeene, 2015; Katz, 1989; van Oorschot, 2006a; Watkins-Hayes and Kovalsky, 2016). This does not mean, however, that the able-bodied have been left to fend for themselves. Welfare societies do put considerable effort into catering for their needs as well, and with the establishment of minimum income protection schemes, try to ensure that no one falls below the lower limit deemed necessary to live a dignified life. Nor does it mean that the old, sick and disabled are given preferential treatment over the able-bodied always and everywhere (i.e., in each country, in each year and in each policy domain). The case made here is that the centuries-old policy distinction between the old, sick and disabled, on the one hand, and the able-bodied of working age, on the other, should be read as a general pattern characterizing the historical development of social welfare provision. As will become clear, that distinction dating back to the early poor laws has manifested itself throughout the development of modern social security into the post-war 'golden age' of welfare expansion, and has surfaced once again in the more recent 'silver age' period of permanent austerity and welfare retrenchment/recalibration.

Although the origins of the modern welfare state are most often traced back to chancellor Bismarck's attempt to protect the German empire from the much feared threat of socialism, through the introduction of social insurance, many European countries had already established public systems of poor relief a few centuries earlier. Most poor laws drew a sharp distinction between the deserving, impotent poor (who were completely incapable of work due to old age, sickness or disability and were given alms and care in charitable poorhouses or through outdoor relief) and the undeserving, able-bodied poor (who were either sent to workhouses, where they were forced to work under appalling conditions, or were banned altogether from the local community) (Cook, 1979; De Swaan, 1988; Gans, 1995; Golding and Middleton, 1982; Kahl, 2005; Katz, 1989; Watkins-Hayes and Kovalsky, 2016). After the initial poor laws came the gradual introduction of modern social insurance legislation, during which the deservingness distinction seems to have persisted. Just as women and children are supposed to be saved first on a sinking ship, the old, the sick and the disabled were the first to have social insurance schemes geared towards them. Across Europe, unemployment insurance was generally introduced much later than the social insurance that covered professional 
injuries and occupational diseases, sickness, disability, maternity, old age and survivorship (Pierson, 1999). ${ }^{7}$ Also in the realm of social assistance, the elderly and disabled were often covered well before the able-bodied, working-age population (Goedemé and Marchal, 2016; Hubl and Pfeifer, 2012). According to Berghman (1999: 17), this is because 'legitimacy is easier to obtain for social contingencies that refer to categories that are taken to be deserving. Hence, the unemployed, on whom doubts are most pronounced, are last to be taken care of' (see also Hubl and Pfeifer, 2012; Kangas, 2000; van Oorschot, 2006a). Interestingly, the same thing is happening all over again in much of the Global South, where most countries have by now put in place old-age, survivors', disability, sickness and work injury benefits, but quite a large number still lack unemployment insurance (Kangas, 2012; Social Security Programs Throughout The World, 2018). ${ }^{8}$ In a similar vein, Ben-Bassat and Dahan (2016) show that across the globe, it is also much more common for states to constitutionally commit to social security rights for the aged and disabled than to guarantee those rights to the unemployed.

Now that we have seen that the old, sick and disabled were treated less harshly in early poor law times, and that the social security schemes targeted at them were generally introduced first, the question remains as to whether in contemporary welfare states they also receive more generous and less conditional social protection compared with the able-bodied unemployed. In (comparative) welfare state literature, three types of policy indicators - each with its own strengths and weaknesses - have been used to measure welfare generosity: social expenditure, social rights and benefit recipiency (Otto, 2018; van Oorschot, 2013). The interesting thing is that despite the fact that they represent very different conceptual approaches and use very different data, all three types of indicators point to the same overall conclusion: there is some evidence suggesting that welfare schemes for the old, sick and disabled are indeed more generous than schemes for the able-bodied unemployed. Social expenditure data, to begin with, consistently show that most countries spend far more on old-age pensions and healthcare than they do on unemployment benefits and social assistance (Boeri et al., 2001; Castles, 2009; Goldschmidt, 2015; Trickey and Walker, 2001; van Oorschot, 2006b). This remains true when the spending figures are adjusted for structural needs, such as the proportion of the population above the retirement age and the number of registered unemployed people (see Appendix 1.1). Of course, even when disaggregated and needsadjusted, social expenditure is at best a very crude measurement of welfare state generosity (Clasen and Siegel, 2007; Green-Pedersen, 2004). A much more fine-grained approach, as it is often framed, is to look at legislative features such as eligibility criteria, benefit levels, duration and coverage - 
which have often been combined into composite generosity indices. The most well-known social rights index is without doubt Esping-Andersen's (1990) de-commodification index, which aims to measure the extent to which social welfare entitlements enable citizens to live independently of market forces. What Esping-Andersen revealed is that, on average, across the 18 industrialized democracies included in his study, old-age pensions de-commodified citizens to a greater extent than sick pay, which in turn de-commodified people more than unemployment benefits. Scruggs and James (2006), who replicated and slightly altered Esping-Andersen's index, but also composed their own benefit generosity index, found the same de-commodification ranking order, in which old-age pensions rank highest, followed respectively by sick pay and unemployment insurance. ${ }^{9}$ In a similar vein, Korpi and Palme (2003: 433) show that, on average, across the same 18 industrialized nations in the 1930-95 period, 'the lowest replacement rates are found in unemployment insurance, while work accident insurance clearly has the highest rates, with sickness cash benefits as the intermediate category'. A similar pattern also unfolds in the realm of social assistance. Categorical social assistance schemes for the old or disabled, where they exist, often provide higher benefit rates and entail less stringent means tests than general social assistance schemes for the able-bodied, working-age population (Goedemé and Marchal, 2016; Hubl and Pfeifer, 2012). However, the social rights approach to welfare generosity has been criticized for taking for granted that what is written in formal law corresponds to what is happening on the ground in everyday policy practice (Otto, 2018; van Oorschot, 2013). In other words, social rights indicators might tell us more about the paper reality than they do about the social reality. For that reason, some scholars have turned to (administrative or survey-based) benefit recipiency data to measure welfare generosity. ${ }^{10}$ Even though the land of benefit recipiency is still very much an uncharted one, it also shows signs that the old, sick and disabled receive more generous social welfare than the able-bodied unemployed. For example, using data from EU-SILC, ${ }^{11}$ van Oorschot (2013: 241) concludes that 'in nearly all countries, amounts are highest for older-age related benefits. Second highest are the amounts for health-related benefits (sick pay and benefits for disabled workers), and for survivor benefits. There are smaller amounts for unemployment benefits, while amounts for social assistance benefits are generally lowest' (see Otto, 2017 for somewhat similar results).

After the 'golden age' of welfare expansion, when full employment was within reach and public resources appeared plentiful, came the socalled 'silver age' of permanent austerity, during which several structural problem pressures (e.g., chronic unemployment, population ageing and economic globalization) generated ongoing processes of retrenchment 
and recalibration of the welfare state (Pierson, 2001; Taylor-Gooby, 2004). Some systematic studies of welfare retrenchment seem to suggest that the knife of austerity has cut deeper for the able-bodied unemployed than for the old, sick and disabled (Goedemé and Marchal, 2016; Green-Pedersen, 2001, 2002; Korpi and Palme, 2003; Lee et al., 2020; Nelson, 2007). ${ }^{12}$ This does not mean, however, that there has been no retrenchment of, for example, old-age pensions, healthcare schemes or disability benefits - there certainly has (Myles and Pierson, 2001; Wendt and Thompson, 2004; Whiteford and Whitehouse, 2006). What it does mean is that unemployment benefits and general social assistance for the working-age population seem to have been the first to be scaled down, while they were also the last to be rolled out. In his in-depth study of retrenchment in Denmark and the Netherlands during the 1982-98 period, Green-Pedersen $(2001,2002)$ showed that in both countries, unemployment benefits were retrenched far more rigorously than old-age pensions. ${ }^{13}$ Through the coding of an enormous amount of legislative welfare reforms over an even longer time span, Lee and colleagues (2020: 181) confirmed that in Denmark, and also in Britain, 'unemployment insurance has experienced many more cutbacks than pensions, which have seen just as many expansions as cutbacks'. Likewise, Nelson (2007) found that as a general rule, old-age pensions faced fewer and less extensive cutbacks than unemployment benefits in 18 industrialized countries between 1990 and 2002. Further, Korpi and Palme (2003) showed that once benefit levels started to be curtailed (which was around 1985), unemployment insurance was generally hit harder than sickness and work accident insurance in most of the industrialized world. Also, within the field of social assistance, it has been argued that categorical schemes for the old have been far less vulnerable to retrenchment than schemes for the able-bodied, working-age population (Goedemé and Marchal, 2016). However, a few other observations seem to run counter to the argument that the able-bodied unemployed have seen the worst of welfare retrenchment. For example, Jensen et al. (2018) showed that this might have been the case in Britain and Denmark, but not in Germany, where unemployment benefits were not retrenched to a greater extent than pensions, and also not in Finland, where the reverse was even true. Further, in Green-Pedersen's analyses (2001, 2002), disability benefits were left largely untouched in Denmark (and were thus, in contrast to unemployment benefits, not curtailed), but not in the Netherlands, where they were actually retrenched more than old-age pensions and unemployment benefits. ${ }^{14}$ Likewise, Nelson (2007) did not report sizeable differences in the extent to which unemployment and sickness insurance have been retrenched in his sample of industrialized nations. This should illustrate once more that the preferential policy treatment of the old, sick and 
disabled over the able-bodied unemployed reflects more of a broad and general pattern characterizing welfare state history than a universal truth that holds always and everywhere.

However, in the silver age of the welfare state, retrenchment is not - as pointed out by van Kersbergen et al. (2014) - 'the only game left in town'. Equally important are processes of welfare state recalibration and restructuring, of which the so-called 'activation turn' is arguably the most profound (Bonoli, 2010). In the past few decades, there has been a gradual, but penetrating shift of focus in contemporary welfare states from passive social protection to active encouragement of labour market participation, or as Cox (1998) puts it, from the welfare state as a safety net offering income security to the welfare state as a trampoline towards (re-) employment (Betzelt and Bothfeld, 2011). Despite the fact that activation has come in many different shapes and sizes, and has therefore become somewhat of a one-size-fits-all umbrella term, there is some scholarly agreement that most activation policies fall into one of two broad categories (Dingeldey, 2007; Taylor-Gooby, 2010; Watts and Fitzpatrick, 2018). On the one hand, 'enabling' activation policies are geared towards the sustainable enhancement of human capital and employability, most often through (typically voluntary) participation in public employment services and training programmes. On the other hand, 'demanding' activation policies are based on the rigorous enforcement of all sorts of work-related obligations imposed on benefit recipients, so as to push them towards employment as soon as possible. There can be little doubt, though, that the entire paradigm shift towards activation has concentrated almost exclusively on the able-bodied unemployed (Lødemel and Trickey, 2001), who have not only been the primary beneficiaries of enabling activation, but also - and perhaps even more so - have been the prime targets of the demanding side of the activation story. It is a well-documented fact that there has been an exponential increase over the past few decades in the volume and strictness of work-related obligations that the able-bodied of working age are required to fulfil in return for receiving unemployment or social assistance benefits (Clasen and Clegg, 2011; Clasen et al., 2001; Knotz, 2018; Lødemel and Trickey, 2001). In most welfare states, claimants are - now more than ever and often from the first days of unemployment being forced to accept jobs well below their educational or previous pay level, to tolerate ever-longer commuting times, to rigidly document and evidence their job-seeking activities and to comply with the many other work-related duties policymakers see fit to impose.

In recent years, however, sickness and disability schemes seem to have been catching up with unemployment and social assistance benefits in terms of welfare conditionality (Larsen, 2008b; Trickey, 2001; Watts and 
Fitzpatrick, 2018). While it is certainly true that activation policies are increasingly being targeted at the sick and partially disabled, these groups are at the same time much more frequently exempted from fulfilling demanding work obligations (Eardley et al., 2000; Sharp, 1999; Trickey, 2001; Watts and Fitzpatrick, 2018). Further, the fully disabled (i.e., those considered completely incapable of work due to ill health) and the elderly have remained largely 'off limits' when it comes to activation policy. Raising the statutory retirement age, or incentivizing voluntary pension deferment, are sometimes conceived as activation measures, but once in receipt of a pension, the elderly are left unbothered. For the time being, it seems unthinkable that pensioners will be required to perform, for example, some kind of workfare-based community service in return for the cash benefits they receive from society. One of the standard arguments against such proposals, closely related to the deservingness criterion of reciprocity (van Oorschot, 2000), would undoubtedly be that pensioners should not be burdened with obligations because they have earned their right to old-age financial assistance through the contributions they have made in the past. However, even for the elderly who receive a pension benefit without having worked a single day in their life, such as spouses with derived pension rights, policymakers seem reluctant to introduce such demanding activation initiatives. It thus seems that there is something about the elderly as a group, perhaps their high level of deservingness, that has shielded them from the activation discourse that has swept across the modern-day welfare state.

\subsection{HEURISTIC MODEL AND OUTLINE OF THE BOOK}

Everything written above points to a remarkable congruence between public opinion and public policy in the domain of social welfare. Those groups that the public consider most deserving of social welfare appear also to receive more generous and less conditional benefits and services compared with those groups deemed relatively less deserving - not always and everywhere, but as a general pattern cutting across welfare state history. ${ }^{15}$ In this book, it is argued that the close correspondence between policy and opinion is the result of a reciprocal relationship between popular deservingness opinions and social welfare policies. On the one hand, popular deservingness beliefs affect public support for social welfare, which through various mechanisms of policy responsiveness in turn shapes how welfare policies are designed and implemented. The most obvious and most frequently mentioned policy responsiveness mechanism is arguably 
that of (re-)election. In a democracy, policymakers are to some extent responsive to the public's wishes (in this case, their deservingness opinions) because they want to win votes and gain office (Brooks and Manza, 2006; Burstein, 2003; Page and Shapiro, 1983). According to this point of view, policymakers, driven by electoral considerations, are inclined to design more beneficial policies for target populations with a more positive popular image, such as the elderly, the sick and the disabled (Cook, 1979; Schneider and Ingram, 1993; van Oorschot, 2006a). However, self-interested re-election motives are only one piece of a larger, more complicated story. As we show in the next chapter, there are several other policy responsiveness mechanisms connecting popular deservingness opinions to social welfare policies. On the other hand, through various mechanisms of policy feedback, welfare policies also have the potential to shape popular notions of deservingness. Once enacted, social policies act as norm-setting and norm-enforcing institutions that might determine which deservingness criteria citizens attach importance to (Larsen, 2006; Lowi, 1964; Mau, 2004; Reeskens and van der Meer, 2017; Rothstein, 1998). When citizens consider who should get what from a means-tested social assistance scheme, for example, the criterion of need presumably plays a particularly pivotal role. However, welfare policies can also influence how target groups are evaluated on the different deservingness criteria (Larsen, 2006; Uunk and van Oorschot, 2017; van Oorschot and Meuleman, 2014). For example, in the case of workers' social insurance, citizens are likely to realize that benefit recipients have contributed through work, and thus rank reasonably high on the criterion of reciprocity.

The reciprocal relationship between popular deservingness opinions and social welfare policies, in which there is continuous covariation (Weissberg, 1976), is summarized in a simple and straightforward manner in the heuristic model displayed in Figure 1.1. Of crucial importance is that the model is an explicitly heuristic one, meaning that it serves mainly as a theoretical blueprint of the book rather than as an empirical model that will be examined in its entirety. That would require extremely fine-grained and high-quality time series or longitudinal data of both popular deservingness opinions and social welfare policies, which are unfortunately unavailable at present. Instead, the primary purpose of the heuristic model is to provide a general theoretical framework in which all empirical chapters can, in one way or another, be situated. It is, in other words, the metaphorical glue that holds the book together.

Chapter 2 elaborates much further on the contents of and the interrelations between the three major social science theories that make up the heuristic model: welfare deservingness, policy responsiveness and policy feedback. The first part of Chapter 2 focuses on the core framework of the 


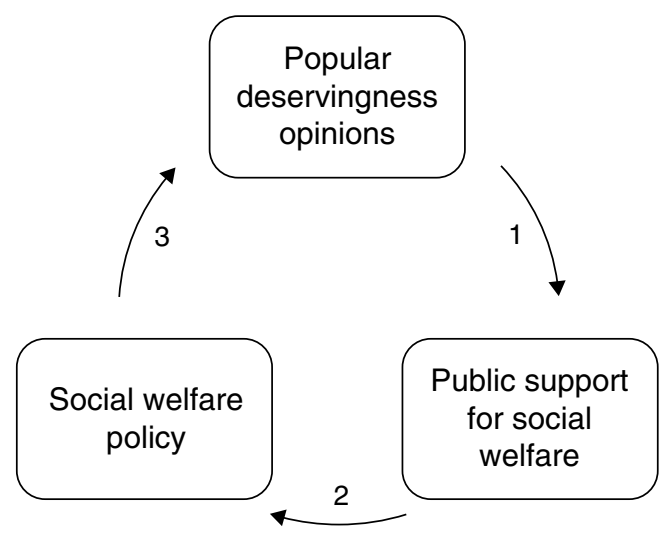

Note: (1) Welfare deservingness theory; (2) policy responsiveness theory; (3) policy feedback theory.

\section{Figure 1.1 Heuristic model: the interaction between welfare deservingness} and welfare policy

book, namely, deservingness theory, and argues that it needs more of two seemingly separate but in fact closely related things: conceptual clarification and empirical examination. After that, we relate welfare deservingness to the perspectives of policy responsiveness and policy feedback.

Chapter 3 then acts as a bridge between the theoretical framework and the empirical chapters by specifying and justifying how the three core concepts of the book's heuristic model - public support for social welfare, popular deservingness opinions and welfare state policies - have been operationalized. In doing so, we also clarify how the book addresses most, but unfortunately not all, of the conceptual and empirical lacunae we have identified in the existing literature.

Chapter 4, which is the first empirical one, looks only at the middle component of the heuristic model: public support for social welfare. In the chapter, we argue that there are sound theoretical and methodological reasons to reassess the oft-cited and pervasive idea that when it comes to social welfare, most citizens - across geographical, temporal and socialstructural boundaries - tend to give preference to the old over the sick and the sick over the unemployed. Based on data from the International Social Survey Programme (ISSP), the main conclusion is that this so-called 'universal dimension of support' (Coughlin, 1980) is less universal than is generally assumed in existing literature. Not only did we find a substantial number of welfare egalitarians, who chose not to differentiate between the old, the sick and the unemployed, we also found that the likelihood 
of ranking the old and sick higher than the unemployed is contingent on the country in which a person lived, the year in which they were surveyed, and above all, the social-structural groups they belonged to. However, among those who did discriminate between the groups, the majority gave the lowest priority to the unemployed. This is one of the reasons why some of the other empirical chapters focus on the particular social risk of unemployment.

Chapter 5, for one, examines popular attitudes towards the social rights (i.e., welfare generosity) and social obligations (i.e., welfare conditionality) of the unemployed. Using Belgian survey data, the chapter concludes that generosity and conditionality appear to be two sides of the same coin, because the two factors are negatively correlated and most of their respective attitudinal drivers are quite similar in strength, yet opposite in direction. Furthermore, it is shown that in addition to self-interest and conventionally recognized ideological beliefs such as egalitarianism and individualism, popular deservingness beliefs - measured here in a novel way - are particularly influential in shaping people's welfare preferences. A stronger emphasis on criteria of deservingness, such as control, attitude and reciprocity, considerably lowers support for social rights and strengthens support for social duties. In terms of the heuristic model, Chapter 5 only examines how popular deservingness beliefs are associated with public support for social welfare, without also relating them explicitly to welfare policies.

Chapter 6 focuses on popular deservingness beliefs, but also addresses their connection to support for social welfare and welfare policies. This chapter is one of the first examples of adopting a qualitative approach to the study of welfare deservingness. Qualitative methods are particularly well suited to address two hitherto unanswered questions in deservingness literature: (1) Which deservingness criteria, if any, do people spontaneously apply when discussing matters of social welfare? (2) What concrete meanings do abstract deservingness criteria have for people, and how do they apply them? Using focus group data gathered in Denmark, Germany and the United Kingdom, we show that citizens made explicit reference to the deservingness criteria of control, reciprocity and need (not to attitude and identity), but also to a number of 'context-related' criteria (e.g., equality/ universalism) that fall outside of the deservingness framework because they refer to the broader context instead of to the characteristics of welfare targets. Our findings also suggest the existence of an institutional logic to welfare preferences, as the focus group participants to a large extent echoed the normative criteria that are most strongly embedded in the institutional structure of their country's welfare regime. In the liberal United Kingdom, for example, financial need was the guiding criterion, while in corporatistconservative Germany it was reciprocity. ${ }^{16}$ 
Chapter 7 follows up on the idea of the institutional embeddedness of welfare attitudes, but shifts the focus of analysis from macro-level welfare regimes to meso-level income benefit schemes. The chapter's main contribution is the development of a theoretical model that postulates that the link between the institutional design of an income benefit and its public support is mediated by three types of popular perceptions: self-interest, programme performance and welfare deservingness. Based on Dutch survey data, the first part of the empirical analysis suggests that these intermediate perceptions are meaningfully related to the institutional set-up of three differently organized benefit schemes in the Netherlands. People's emphasis on deservingness criteria, for example, appears to be in accordance with the normative principles embodied in the benefit schemes. That is, whereas the reciprocity criterion is stressed most with regard to workers' unemployment insurance, the need criterion is clearly most important for the social assistance scheme. The second part of the analysis shows that all three types of perceptions affect public support for welfare allocation to the target groups of the benefit schemes. The higher citizens' perceived self-interest in a welfare programme and the better its perceived performance, the stronger the support for the distribution of public resources to its target group. Further, the more strongly a person emphasizes the criteria of reciprocity or need, the more he or she opposes welfare provision.

Chapter 8 builds further on the relationship between welfare deservingness and welfare policy by examining how unemployment policies - and their degree of selectivity, generosity and conditionality in particular - feed back into popular deservingness perceptions concerning the unemployed. Using data from the European Social Survey (ESS), our results show that comparatively generous and unconditional unemployment policies fuel the perception that most unemployed people have a relatively good standard of living and are not actively looking for a job. Europeans who hold such deservingness beliefs are also considerably less supportive of government responsibility to ensure a decent standard of living for the unemployed, net of their social-structural background and ideological orientations. These findings suggest that one of the policy recommendations most often made by international institutions such as the International Monetary Fund (IMF) and the European Union (EU) - that is, to make unemployment benefits less attractive by lowering the benefit levels and increasing the work requirements - could potentially, and perhaps counterintuitively, boost public support for unemployment provision in the long run. ${ }^{17}$ However, as a precautionary note, it should be mentioned that the crosssectional nature of the data limits our ability to demonstrate empirically that the causal chain actually runs from public policy to public opinion, instead of the other way around. 
The same goes, mutatis mutandis, for Chapter 9, which comes closest to the policy responsiveness part of the heuristic model. The starting point for the chapter is the absence of fierce public resistance to the retrenchment of unemployment insurance that has taken place in Denmark and the Netherlands over the past 30 years. The lack of public opposition is somewhat puzzling, because both the Dutch and the Danish unemployment schemes have traditionally had relatively large and well-organized welfare constituencies. The core argument put forward in Chapter 9 is that in addition to the waning power of the trade unions, the role of changing ideas concerning the need for reform and the successful application of elite blame-avoidance strategies, the relatively harsh deservingness assessment of the unemployed among the constituencies of unemployment insurance has been pivotal for the absence of strong resistance. Using Dutch and Danish survey data, the chapter demonstrates this mechanism by showing that large numbers of the constituencies of unemployment insurance (which is operationalized as self-reported benefit receipt and experience of unemployment) evaluate the unemployed negatively on the deservingness criteria of control, attitude, reciprocity, identity and need. These deservingness perceptions are, in turn, strongly correlated to support for reducing the social rights of the unemployed and expanding their social obligations.

The final chapter concludes by summarizing the book's most important contributions to welfare deservingness literature. For each contribution, we highlight some of the main findings and their implications, but also identify remaining knowledge gaps and offer promising avenues for future research. For example, one of the book's major contributions is that it puts the welfare deservingness framework in a much broader perspective, by comparing it in unprecedented detail with alternative explanatory frameworks. In the empirical part of the book, we show that deservingness opinions have a strong and stable impact on support for social welfare one that often outweighs the impact of other, well-established explanatory factors (i.e., self-interest, ideology and performance evaluations). The broader implication of this finding is that deservingness should perhaps be added as a third protagonist in the welfare attitudes scene, next to the two 'traditionally recognized' others: self-interest and (political) ideology. What the book lacks, however, are empirical examinations of the intricate ways in which the different explanatory factors interact with one another; which is an important task for future researchers.

Before proceeding to the next, theoretical chapter, however, three concluding remarks should nuance and put into broader perspective the deservingness argument presented in this book. First, we acknowledge that deservingness is only one factor shaping public support for social welfare. As argued above, alongside popular deservingness opinions, 
self-interest considerations, general ideological beliefs and performance evaluations may also be of crucial importance in understanding public support for social welfare. This implies that policy responsiveness and policy feedback mechanisms do not only work through deservingness, but also through some of the other well-known drivers of welfare attitudes (see e.g., Larsen, 2006: 14; Wendt et al., 2011: 22). Second, public opinion is only one - and presumably not even the most important - factor shaping social policy; there are of course many others (Burstein, 2020). In the case of welfare retrenchment, for example, there are several alternative explanations besides public opinion as to why some social security schemes are more vulnerable to cutbacks than others, including programmatic characteristics such as the degree of universalism (Nelson, 2007; Pierson, 1994), mode of financing (Anderson, 2001) or administrative structure (Bonoli et al., 2000), but also the schemes' connection to the labour market (Green-Pedersen, 2002) and the political power of their respective target groups (Schneider and Ingram, 1993). Third, social welfare policy is just one factor shaping deservingness and welfare support. There are many other contextual determinants of popular welfare attitudes, including demographic developments, such as population ageing, migration and ethnic heterogeneity (Alesina and Glaeser, 2004; Larsen, 2011; Naumann, 2018), cultural influences, such as a country's religious or ideological heritage (Alesina and Fuchs-Schündeln, 2007; VanHeuvelen, 2014), political discourse (Svallfors et al., 2012), media coverage on social welfare (Larsen and Dejgaard, 2013), and last but not least, the state of the economy (Blekesaune, 2007). One of the most established findings in deservingness literature, for example, is that higher levels of unemployment tend to trigger public awareness that the jobless are not personally responsible for their plight, but are victims of circumstance (the criterion of control), which in turn increases public support for government-sponsored unemployment provision (Jeene, 2015; Larsen, 2006). Together, these concluding remarks should, above all, make clear that despite its explicit focus on deservingness, this book neither denies nor ignores alternative explanatory frameworks. Deservingness is, after all, only one - albeit a very fruitful - analytical lens through which to explore the complex world of social welfare.

\section{NOTES}

1. To make it clear from the start, the focus of this book is on social welfare, defined here as directly provided welfare benefits and services for which governments bear some political responsibility (e.g., old-age pensions, healthcare, unemployment insurance, disability benefits), and not so much on its close relatives: fiscal and occupational welfare (Sinfield, 1978; Titmuss, 1958). 
2. However, see Boeri et al. (2001) for some contrasting findings.

3. It is here that this book differs from much - mainly American - literature that makes a dichotomous distinction between the deserving poor and the undeserving poor (Appelbaum, 2001; Gans, 1995; Katz, 1989; Watkins-Hayes and Kovalsky, 2016). In our view, deservingness is a continuum rather than a dichotomy, ranging from 'very undeserving' to 'very deserving', with a host of in-between positions (van Oorschot and Roosma, 2017).

4. This is in line with the conclusion drawn by many independent researchers that public support for the welfare state, and the various programmatic components it comprises, tends to be strong and stable (Cook and Barrett, 1992; Coughlin, 1980; Kumlin and Stadelmann-Steffen, 2014; Taylor-Gooby, 1985).

5. As shown by Gilens (1999) and others (Smith, 1987; Soss and Schram, 2007), one glaring exception in the US context is 'welfare', which in the American sense of the word refers to means-tested public assistance for poor, often female-headed, single-parent families, and receives very little public support in American society.

6. To 'feast' is admittedly somewhat of an exaggeration, as welfare schemes rarely provide citizens with an abundance of resources allowing them to live a life of luxury. Nevertheless, Boulding's terminology does help to make the point that the old, the sick and the disabled are often given more generous social welfare than the able-bodied unemployed.

7. One could argue that the relatively late introduction of family allowances/child benefits, often even after unemployment insurance, deviates from this chronological pattern. However, although many commentators have claimed so, there is less evidence that children, or alternatively their parents, are particularly deserving of social welfare in the public's mind (Wendt et al., 2011). One important issue in this regard is that having children is often regarded as a private rather than a public responsibility (Cook, 1979; Cook and Barrett, 1992; Svallfors, 1991).

8. However, it should be noted that in developing countries, social security benefits are often reserved for privileged civil servants, whose tenure tends to preclude the need for unemployment provision. Further, the relatively large informal economies that exist in these countries might render the organization of contributory unemployment insurance particularly difficult. However, the same could of course also be said of other social insurance schemes, such as many contributory old-age pensions and disability benefits (Brady and Bostic, 2015).

9. In our view, both Esping-Andersen (1990) and Scruggs and James (2006) actually overestimate unemployment benefit generosity and underestimate pension generosity. For unemployment benefits, both used the replacement rates during the initial six months of unemployment, when benefits are at their most generous. Had they opted for replacement rates over longer-term unemployment, a different picture would have emerged, as most unemployment benefits are degressive; that is, they decline with longer periods of unemployment. The main issue with the pension generosity index is that it only takes public pensions into account, and thus completely ignores the fact that many countries have multi-pillar systems in which public pensions are topped up with private and occupational pensions that are officially not 'public', but nevertheless tend to be heavily regulated and subsidized by governments.

10. Another way to get closer to policy practice is to study how generously different target groups are treated by street-level policy administrators when formal legislation leaves room for discretion (Altreiter and Leibetseder, 2015; De Wilde, 2017; Knegt, 1987; Schram et al., 2009; Thorén, 2008; Watkins-Hayes and Kovalsky, 2016).

11. The EU Statistics on Income and Living Conditions (EU-SILC) is the reference source for comparative statistics on income distribution and social inclusion in the European Union.

12. In addition to such systematic evidence, there is also plenty of anecdotal evidence which is nevertheless usually provided by welfare state experts - that unemployment benefits were hit particularly hard in the era of welfare retrenchment when compared 
with old-age pensions (see e.g. Raven et al., 2011 for the Netherlands; and Taylor and Taylor-Gooby, 2015 for the United Kingdom) or sickness/disability benefits (see e.g. Cappelen et al., 2018 for Norway).

13. In Denmark, pensions were actually expanded to a considerable extent.

14. However, before treating this as an anomaly to the deservingness distinction, it should be noted that most commentators agree on the exceptional and extreme generosity that used to characterize the Dutch disability system (Wet op de arbeidsongeschiktheidsuitkering, WAO). The system was so easily accessible, so generous and so unconditional that by the mid-1980s, an astonishing 7 per cent of the working-age population in the Netherlands were on disability benefits. Accordingly, it should come as no surprise that Dutch disability benefits suffered serious downscaling (Hoogenboom, 2011; van Oorschot, 2006b).

15. We are certainly not the first to point out the close correspondence between welfare deservingness and welfare policy (Cook, 1979: 40; Cook and Barrett, 1992: 95, 144; Handler and Hasenfeld, 1991: 11; Hubl and Pfeifer, 2012; Jeene, 2015: 14; Skocpol, 1992: 149; van Oorschot, 2006a: 23-4; Watkins-Hayes and Kovalsky, 2016: 199).

16. In social-democratic Denmark, it proved impossible to single out one dominant normative criterion. Instead, the Danish participants seemed torn between the criteria of need, reciprocity and equality/universalism.

17. Another oft-cited policy recommendation - i.e., to increase reliance on means-tested targeting in social security provision (Schoukens, 2016) - might be less consequential for public opinion on unemployment benefits, as the degree of selectivity does not appear to be related to popular perceptions concerning the needs and job-seeking efforts of the unemployed. 